\title{
Adsorption of Nickel Ion by Low Cost Carbon- Kinetic, Thermodynamic and Equilibrium Studies
}

\author{
V. VIJAYAKUMARAN, S. ARIVOLI* and S. RAMUTHAI ${ }^{\S}$ \\ *Department of Chemistry, \\ H. H. the Rajah's Government College, Pudukkottai-622 001, India. \\ ${ }^{\S}$ Department of Chemistry, \\ Seethalakshmi Achi College for Women, Pallathur-630 107, India. \\ arivu3636@yahoo.com
}

Received 20 May 2009; Revised 5 August 2009; Accepted 15 August 2009

\begin{abstract}
A carbonaceous adsorbent prepared from an indigenous waste, by acid treatment was tested for its efficiency in removing nickel ion. The process parameters studied include agitation time, initial metal ion concentration, carbon dose, $\mathrm{pH}$ and temperature. The adsorption followed first order reaction equation and the rate is mainly controlled by intraparticle diffusion. Freundlich and Langmuir isotherm models were applied to the equilibrium data. The adsorption capacity $\left(\mathrm{Q}_{\mathrm{m}}\right)$ obtained from the Langmuir isotherm plot were found to around $43 \mathrm{mg} / \mathrm{g}$ at an initial $\mathrm{pH}$ of 7.0. The temperature variation study showed that the nickel ions adsorption is endothermic and spontaneous with increased randomness at the solid solution interface. Significant effect on adsorption was observed on varying the $\mathrm{pH}$ of the nickel ion solutions. The Langmuir and Freundlich adsorption isotherms obtained, positive $\Delta \mathrm{H}^{0}$ value, $\mathrm{pH}$ dependent results and desorption of metal ions in mineral acid suggest that the adsorption of nickel ion on MCC involves chemisorption as well as physisorption mechanism.
\end{abstract}

Keywords: Activated carbon, Nickel ion, Adsorption isotherm, Equilibrium, Kinetic and Thermodynamic parameters, Intraparticle diffusion.

\section{Introduction}

The problems of the ecosystem are increasing with developing technology. Heavy metal pollution is one of the main problems. Toxic metal compounds coming to the earth's surface not only reach the earth's waters (seas, lakes, ponds and reservoirs) but can also contaminate ground water in trace amounts by leaching from the soil. Therefore, the earth's water may contain various toxic metals. 
Metal ion such nickel produces undesirable effects on human and animal life even in low concentrations. In recent years many researchers have studied the removal of different heavy metal ions including chromium, nickel, iron and copper from the water. Wastewaters from industries released in to nearby land or rivers without any treatment because the conventional treatment methods are not cost effective in the Indian context. On the other hand, low cost technologies never allow a wishful metal ion removal and it has certain disadvantages. Adsorption is one of the most effective methods and activated carbon is the preferred adsorbent widely employed to treat wastewater containing different classes of metal ions recognizing the economic drawback of commercial activated carbon. Many investigators have studied the feasibility of using inexpensive alternative materials like pearl millet husk, date pits, saw dust, buffing dust of leather industry, coir pith, crude oil residue, tropical grass, olive stone and almond shells, pine bark, wool waste, coconut shell etc., as carbonaceous precursors for the removal of metal ion from water and wastewater ${ }^{1-3}$. The present study undertaken to evaluate the efficiency of a carbon adsorbent prepared form acid activated morinda coreia buch-ham bark for the removal of nickel ion aqueous solution. In order to design adsorption treatment systems, knowledge of kinetic and mass transfer process is essential. In this paper, the applicability of kinetic and mass-transfer models for the adsorption of nickel ion onto activated carbon is reported in well defined manner.

\section{Experimental}

\section{Materials and Methods}

Carbon was prepared by treating air-dried morinda coreia buch-ham bark (MCC) with con sulphuric acid in a weight ratio of $1: 1$. The resulting black product was kept in a furnace maintained at $500{ }^{\circ} \mathrm{C}$ for 12 hours followed by washing with water until free from excess acid and dried at $150 \pm 5{ }^{\circ} \mathrm{C}$. The carbon product obtained was ground and the portion retained between 30 and $50 \mu \mathrm{m}$ sieves was used in all the experiments. All chemicals supplied by S.d. fine chemicals with high purity.

\section{Batch equilibration method}

All experiments were carried out at $30,40,50$ and $60^{\circ} \mathrm{C}$ temperature in batch mode. Batch mode was selected because of its simplicity and reliability. The experiments were done in different Erlenmeyer glass flasks of $100 \mathrm{~mL}$ capacity. Prior to each experiment, a predetermined amount of absorbent was added to each flask. The stirring was kept constant (120 rpm) for each run throughout the experiment to ensure equal mixing. Each flask was filled with a known volume of sample before commencing stirring such as metal ion solutions with an initial concentration of $10 \mathrm{mg} / \mathrm{L}$ to $50 \mathrm{mg} / \mathrm{L}$. The flask containing the sample was withdrawn from the shaker at the predetermined time interval, filtered and the residual concentration of the metal ion was measured.

\section{Effect of variable parameters}

\section{Dosage of adsorbents}

Different doses consisting of 10 to $250 \mathrm{mg} / 50 \mathrm{~mL}$ of the adsorbent is mixed with the nickel ion solution and the mixture was agitated in a mechanical shaker. The percentage of adsorption for different doses was determined by keeping all other factors constant.

\section{Initial concentration}

In order to determine the rate of adsorption, experiments were conducted with different initial concentrations of nickel ions ranging from 10 to $50 \mathrm{mg} / \mathrm{L}$. All other factors were kept constant. 


\section{Contact time}

The effect of period of contact between the adsorbent and adsorbate on the removal of the nickel ions in a single cycle was determined by keeping particle size, initial concentration, dosage, $\mathrm{pH}$, and temperature constant.

\section{Initial $\mathrm{pH}$}

Adsorption experiments were carried out at a range of $\mathrm{pH}$ of the solution i.e. 3-10. The acidic and alkaline $\mathrm{pH}$ of the medium was maintained by adding the required amounts of hydrochloric acid and sodium hydroxide solutions. The parameters like particle size of the adsorbents, and temperature were kept constant while carrying out the experiments.

\section{Other ions}

Adsorption studies of a specific metal ion in the presence of chloride ions were experimentally verified using the adsorbents. This involved the determination of the percentage of metal ion adsorbed from $30 \mathrm{mg} / \mathrm{L}$ of initial concentration of the metal ion solution with varying concentration of the added ion keeping all other factors constant.

\section{Temperature}

The adsorption experiments were performed at four different temperatures viz., 30, 40, 50 and $60{ }^{\circ} \mathrm{C}$ in a thermostated shaker machine (Remi, India). The constancy of the temperature was maintained with an accuracy of $\pm 0.5^{\circ} \mathrm{C}$.

\section{Zero point charge}

The $\mathrm{pH}$ at the potential of zero charge of the carbon (pHzpc) was measured using the $\mathrm{pH}$ drift method. The $\mathrm{pH}$ of the solution was adjusted by using $0.01 \mathrm{M}$ sodium hydroxide or hydrochloric acid. Nitrogen was bubbled through the solution at $25{ }^{0} \mathrm{C}$ to remove the dissolved carbon dioxide. $50 \mathrm{mg}$ of the activated carbon was added to $50 \mathrm{~mL}$ of the solution. After stabilization, the final $\mathrm{pH}$ was recorded. The graphs of final $\mathrm{pH}$ versus initial $\mathrm{pH}$ used to determine the zero point charge of the activated carbon ${ }^{4}$.

\section{Titration studies}

According to Boehm ${ }^{4}$ only strong acidic carboxylic acid groups are neutralized by sodium bicarbonate, where as those neutralized by sodium carbonate are thought to be lactones, lactol and carboxyl group. The weakly acidic phenolic groups only react with strong alkali, sodium hydroxide. Therefore, by selective neutralization using bases of different strength, the surface acidic functional group in carbon can be characterized both quantitatively and qualitatively. Neutralization with hydrochloric acid characterizes the amount of surface basic groups that are, for example, pyrones and chromenes. The basic properties have described to surface basic groups and the pi electron system of carbon basal planes. The results indicate that the activated carbon used may possesses acidic oxygen functional group on their surface and this is supported well by their respective zero point charge values. The results obtained from the above characterization studies are given in the Table 1.

\section{Regeneration studies}

The regeneration of the adsorbed carbon is done by using $0.2 \mathrm{M}$ mineral acids and sodium chloride solutions.

\section{Results and Discussion}

\section{Characterization of the adsorbent}

Activated carbons are a widely used adsorbent due to its high adsorption capacity, high surface area, micro porous structure and high degree of surface respectively. The wide 
usefulness of carbon is a result of their specific surface area, high chemical and mechanical stability. The chemical nature and pore structure usually determines the sorption activity. The physico chemical properties of the chosen adsorbent are listed in following Table 1.

Table 1. Characteristics of the adsorbent

\begin{tabular}{lc}
\hline \multicolumn{1}{c}{ Properties } & MCC \\
\hline Particle size, mm & 0.055 \\
Density, g/cc & 0.3575 \\
Moisture content, \% & 2.25 \\
Loss on ignition, \% & 82 \\
Acid insoluble matter, \% & 2.5 \\
Water soluble matter, \% & 0.32 \\
$\mathrm{pH}$ of aqueous solution & 6.85 \\
$\mathrm{pH}_{\text {zpc }}$ & 6.35 \\
Surface groups, m equiv/g & \\
i) Carboxylic acid & 0.325 \\
ii) Lactone, lactol & 0.049 \\
iii) Phenolic & 0.061 \\
iv) Basic (pyrones and & 0.036 \\
\hline
\end{tabular}

Effect of carbon concentration

The adsorption of the metal ion on carbon was studied by varying the carbon concentration $(10-250 \mathrm{mg} / 50 \mathrm{~mL})$ for nickel ion concentration of $30 \mathrm{mg} / \mathrm{L}$. The percentage of adsorption increased with increase in the carbon concentration (Figure 1). This was attributed to increased carbon surface area and availability of more adsorption sites ${ }^{5,6}$.

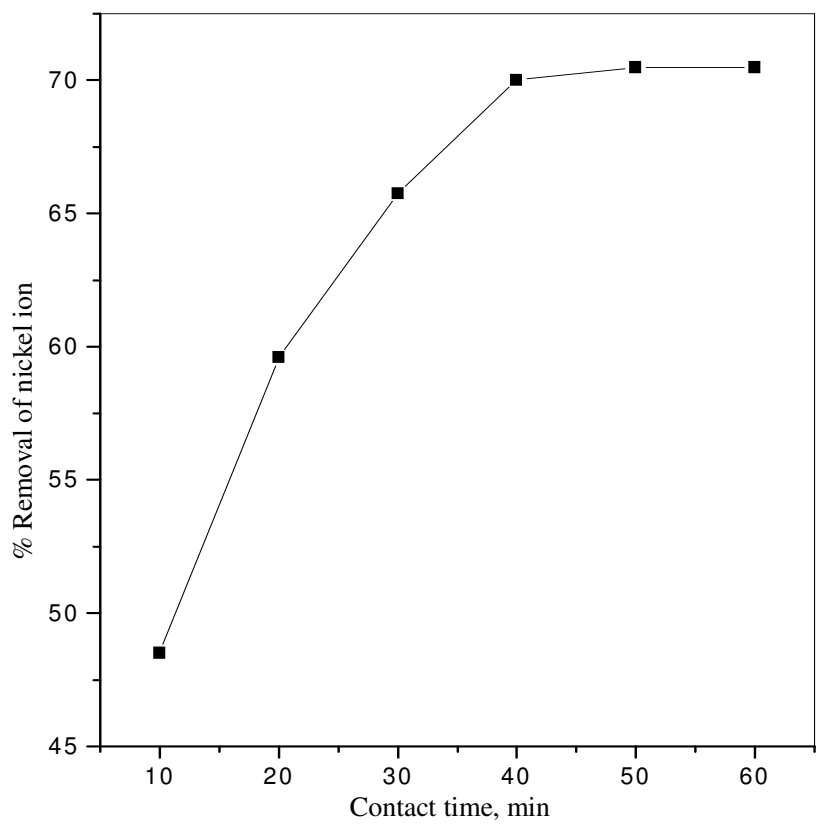

Figure 1. Effect of contact time on the adsorption of nickel ion.

$[\mathrm{Ni}]=30 \mathrm{mg} / \mathrm{L} ; \mathrm{pH}=7$; Adsorpbent dose $=50 \mathrm{mg} / 50 \mathrm{~mL}$. 


\section{Effect of contact time and initial nickel ion concentration}

The experimental results of adsorptions of nickel ion on the activated carbon at various concentrations $(10,20,30,40$ and $50 \mathrm{mg} / \mathrm{L})$ with contact time are shown in Figure 2. The equilibrium data were collected in Table 2 reveals that, percent adsorption decreased with increase in initial nickel ion concentration, but the actual amount of nickel ion adsorbed per unit mass of carbon increased with increase in metal ion concentration. It means that the adsorption is highly dependent on initial concentration of nickel ion. It is because of that at lower concentration, the ratio of the initial number of nickel ion to the available surface area is low subsequently the fractional adsorption becomes independent of initial concentration. However, at high concentration the available sites of adsorption becomes fewer and hence the percentage removal of nickel ion is dependent upon initial concentration. Equilibrium have established at 40 minutes for all concentrations. Figure 1 reveals that the curves are single, smooth, and continuous, leading to saturation, suggesting the possible monolayer coverage of the nickel ion on the carbon surface ${ }^{5,6}$.

\section{Adsorption isotherm}

The experimental data analyzed according to the linear form of the Langmuir $^{7}$ and Freundlich ${ }^{8}$ isotherms.

The Langmuir isotherm represented by the following equation

$$
\mathrm{C}_{\mathrm{e}} / \mathrm{Q}_{\mathrm{e}}=1 / \mathrm{Q}_{\mathrm{m}} \mathrm{b}+\mathrm{C}_{\mathrm{e}} / \mathrm{Q}_{\mathrm{m}}
$$

Where $\mathrm{C}_{\mathrm{e}}$ is the equilibrium concentration $(\mathrm{mg} / \mathrm{L}), \mathrm{Q}_{\mathrm{e}}$ is the amount adsorbed at equilibrium $\left(\mathrm{mg} / \mathrm{g}\right.$ ) and $\mathrm{Q}_{\mathrm{m}}$ and $\mathrm{b}$ is Langmuir constants related to adsorption efficiency and energy of adsorption, respectively. The linear plots of $\mathrm{C}_{\mathrm{e}} \mathrm{Q}_{\mathrm{e}}$ versus $\mathrm{C}_{\mathrm{e}}$ suggest the applicability of the Langmuir isotherms (Figure 3). Values of $\mathrm{Q}_{\mathrm{m}}$ and $\mathrm{b}$ were determined from slope and intercepts of the plots and are presented in Table 3. From the results, it is clear that the value of adsorption efficiency $\mathrm{Q}_{\mathrm{m}}$ and adsorption energy $b$ of the carbon increases on increasing the temperature. From the values we can conclude that the maximum adsorption corresponds to a saturated monolayer of adsorbate molecules on adsorbent surface with constant energy and no transmission of adsorbate in the plane of the adsorbent surface ${ }^{9,10}$. The trend shows that the adsorbent prefers to bind acidic ions and that speciation predominates on sorbent characteristics, when ion exchange is the predominant mechanism. Further, it confirms the endothermic nature of the processes involved in the system. To confirm the adorability of the adsorption process, the separation factor $\left(\mathrm{R}_{\mathrm{L}}\right)$ has calculated and presented in Table 4 . The values were found to be between 0 and 1 and confirm that the ongoing adsorption process is favourable ${ }^{11}$

The Freundlich equation have also employed for the adsorption of nickel ion on the adsorbent. The Freundlich isotherm have represented as

$$
\log \mathrm{Q}_{\mathrm{e}}=\log \mathrm{K}_{\mathrm{f}}+1 / \mathrm{n} \log \mathrm{C}_{\mathrm{e}}
$$

Where $\mathrm{Q}_{\mathrm{e}}$ is the amount of nickel ion adsorbed $(\mathrm{mg} / \mathrm{g}), \mathrm{C}_{\mathrm{e}}$ is the equilibrium concentration of metal ion in solution $(\mathrm{mg} / \mathrm{L})$ and $\mathrm{K}_{\mathrm{f}}$ and $\mathrm{n}$ are constants incorporating all factors affecting the adsorption capacity and intensity of adsorption, respectively. Linear plot of $\log \mathrm{Q}_{\mathrm{e}}$ versus $\log \mathrm{C}_{\mathrm{e}}$ shows that the adsorption of nickel ion follows the Freundlich isotherm (Figure 4). Values of $K_{f}$ and $n$ were found and given in the Table 5, shows the increase of negative charge on the surface that enhances the electrostatic force like Van der Waal's between the carbon surface and metal ion, which increases the adsorption of nickel ion. The values clearly show that dominance in adsorption capacity. The intensity of adsorption is an indicative of the bond energies between nickel ion and adsorbent and the possibility of slight chemisorptions rather than physisorption ${ }^{10,11}$. The possibility of multilayer adsorption of metal ion through the percolation process cannot be ruled out. However, the values of $n$ is greater than one indicating the adsorption is much more favourable ${ }^{12,13}$. 
Table 2. Equilibrium parameters for the adsorption metal ion onto MCC.

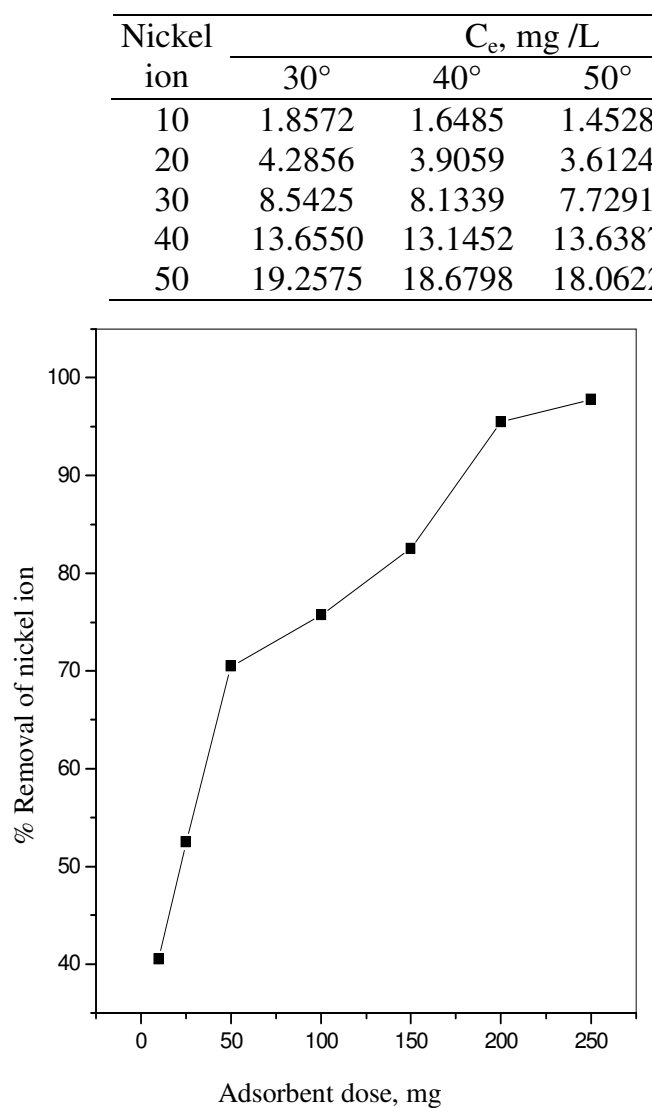

Figure 2. Effect of adsorbent dose on the adsorption of nickel ion.

$[\mathrm{Ni}]=30 \mathrm{mg} / \mathrm{L} ; \mathrm{pH}=7$; Contact time $=60 \mathrm{~min}$

Metal ions Removed, \%

\begin{tabular}{ccccccccc}
\multicolumn{4}{c}{$\mathrm{Q}_{\mathrm{e}}, \mathrm{mg} / \mathrm{g}$} & \multicolumn{4}{c}{ Metal ions Removed, \% } \\
\hline $60^{\circ}$ & $30^{\circ}$ & $40^{\circ}$ & $50^{\circ}$ & $60^{\circ}$ & $30^{\circ}$ & $40^{\circ}$ & $50^{\circ}$ & $60^{\circ}$ \\
\hline 1.2621 & 8.1428 & 8.3515 & 8.5472 & 8.7379 & 81.43 & 83.51 & 85.47 & 87.37 \\
3.3059 & 15.7144 & 16.30941 & 16.3876 & 16.6941 & 78.57 & 80.47 & 81.93 & 83.47 \\
7.4199 & 21.4575 & 21.8661 & 22.2709 & 22.5801 & 71.52 & 72.88 & 74.23 & 75.26 \\
13.5288 & 26.3450 & 26.8548 & 26.3613 & 26.4712 & 65.86 & 67.13 & 65.90 & 66.17 \\
17.6017 & 30.7425 & 31.3202 & 31.9378 & 32.3983 & 61.48 & 62.64 & 63.87 & 64.79 \\
\hline
\end{tabular}

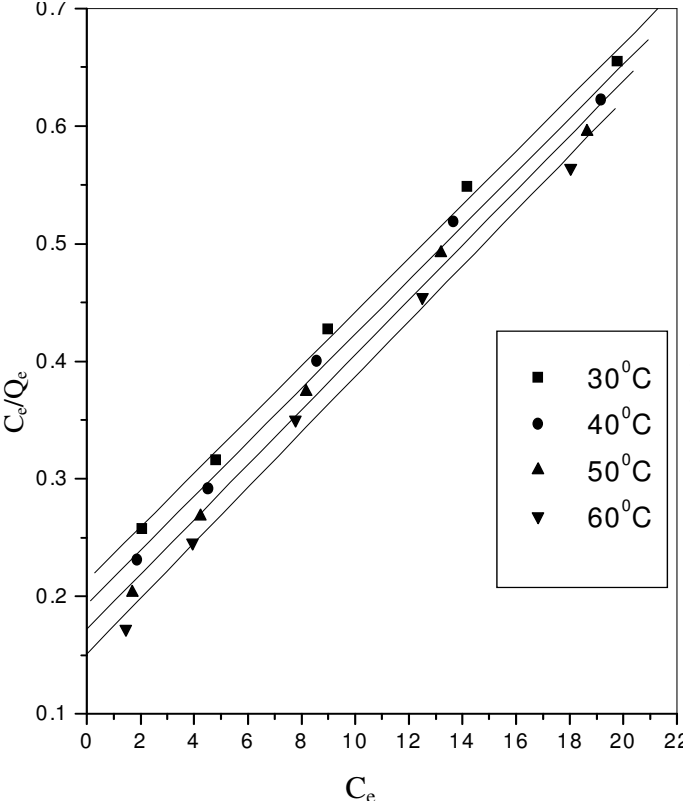

Figure 3. Langmuir isotherm for the adsorption of nickel ion.

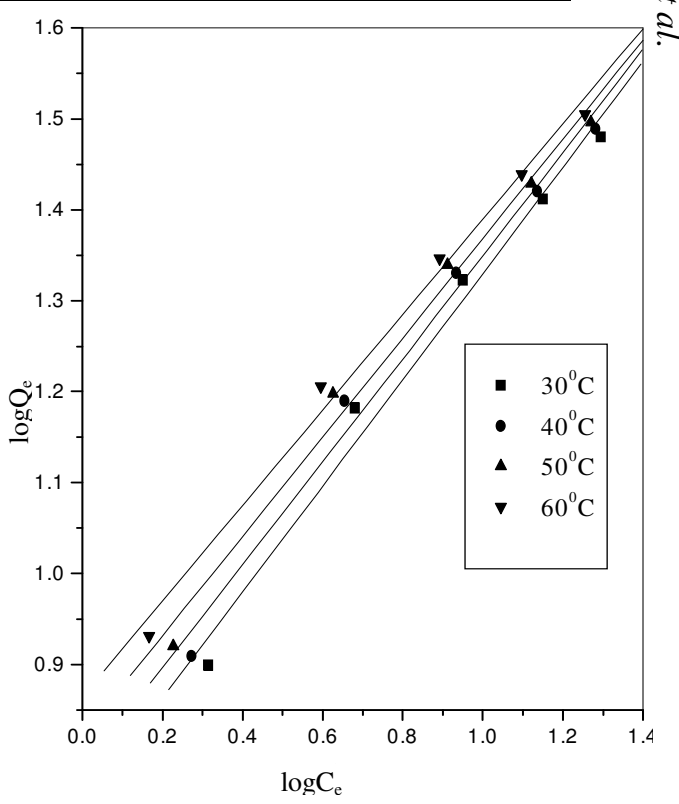

Figure 4. Freundlich isotherm for the adsorption of nickel ion. 
Table 3. Langmuir isotherm results.

\begin{tabular}{ccccc}
\hline Metal ion & Temp & \multicolumn{2}{c}{ Statistical parameters } & Constants \\
\hline & ${ }^{\circ} \mathrm{C}$ & $r^{2}$ & $\mathrm{Q}_{\mathrm{m}}$ & $\mathrm{b}$ \\
Nickel ion & $30^{\circ}$ & 0.9982 & 43.82 & 0.11 \\
adsorption & $40^{\circ}$ & 0.9711 & 43.54 & 0.12 \\
& $50^{\circ}$ & 0.9667 & 42.86 & 0.14 \\
& $60^{\circ}$ & 0.9655 & 42.44 & 0.16 \\
\hline
\end{tabular}

Table 4. Dimensionless separation factor $\left(\mathrm{R}_{\mathrm{L}}\right)$.

\begin{tabular}{ccccc}
\hline Nickel ion, $\mathrm{mg} / \mathrm{L}$ & \multicolumn{4}{c}{ Temperature, ${ }^{\circ} \mathrm{C}$} \\
\hline & $30^{\circ}$ & $40^{\circ}$ & $50^{\circ}$ & $60^{\circ}$ \\
10 & 0.483 & 0.454 & 0.416 & 0.384 \\
30 & 0.318 & 0.294 & 0.263 & 0.238 \\
40 & 0.232 & 0.217 & 0.192 & 0.172 \\
50 & 0.185 & 0.172 & 0.151 & 0.135 \\
& 0.163 & 0.142 & 0.125 & 0.111 \\
\hline
\end{tabular}

Table 5. Freundlich isotherm results.

\begin{tabular}{ccccc}
\hline Metal ion & Temp & \multicolumn{2}{c}{ Statistical parameters } & Constants \\
\hline \multirow{3}{*}{ Nickel ion } & $\left({ }^{\circ} \mathrm{C}\right)$ & $r^{2}$ & $\mathrm{k}_{\mathrm{f}}$ & $\mathrm{n}$ \\
adsorption & $30^{\circ}$ & 0.9920 & 1.79 & 1.71 \\
& $40^{\circ}$ & 0.9985 & 1.76 & 1.77 \\
& $50^{\circ}$ & 0.9770 & 1.73 & 1.83 \\
& $60^{\circ}$ & 0.9962 & 1.69 & 1.91 \\
\hline
\end{tabular}

\section{Effect of temperature}

The adsorption capacity of the carbon increased with increase in the temperature of the system from $30^{\circ}-60^{\circ} \mathrm{C}$. Thermodynamic parameters such as change in free energy $\left(\Delta \mathrm{G}^{\circ}\right)$, enthalpy $\left(\Delta \mathrm{H}^{\circ}\right)$ and entropy $\left(\Delta \mathrm{S}^{\circ}\right)$ were determined using the following equations ${ }^{11,12,15,16}$

$$
\begin{aligned}
\mathrm{K}_{0} & =\mathrm{C}_{\text {solid }} / \mathrm{C}_{\text {liquid }} \\
\Delta \mathrm{G}^{\circ} & =-\mathrm{RT} \ln \mathrm{K}_{\mathrm{O}} \\
\log \mathrm{K}_{0} & =\Delta \mathrm{S}^{\circ} /(2.303 \mathrm{RT})-\Delta \mathrm{H}^{\circ} /(2.303 \mathrm{RT})
\end{aligned}
$$

Where, $K_{0}$ is the equilibrium constant, $C_{\text {solid }}$ is the solid phase concentration at equilibrium $(\mathrm{mg} / \mathrm{L}), \mathrm{C}_{\text {liquid }}$ is the liquid phase concentration at equilibrium $(\mathrm{mg} / \mathrm{L}), \mathrm{T}$ is the temperature in Kelvin and $\mathrm{R}$ is the gas constant. The $\Delta \mathrm{H}^{\circ}$ and $\Delta \mathrm{S}^{\circ}$ values obtained from the slope and intercept of van't Hoff plots have presented in Table 6 . The values are with in the range of 1 to $93 \mathrm{~kJ} / \mathrm{mol}$ indicates the favourability of physisorption. The positive values of $\Delta \mathrm{H}^{\circ}$ show the endothermic nature of adsorption and it governs the possibility of physical adsorption. Because in the case of physical adsorption, while increasing the temperature of the system, the extent of metal ion adsorption increases, this rules out the possibility of chemisorptions. However, the very low $\Delta \mathrm{H}^{\circ}$ value depicts nickel ion is physisorbed onto adsorbent ${ }^{12,13,15}$

The negative values of $\Delta \mathrm{G}^{\circ}$ (Table 6) shows the adsorption is highly favourable for nickel ion. However, it indicates that the metal ion adsorption was spontaneous. The positive values of $\Delta S^{\circ}$ (Table 6) shows the increased disorder and randomness at the solid solution interface of with adsorbent MCC. While the adsorption there are some structural changes in the nickel ion and the adsorbent occur. The adsorbed water molecules, which have displaced by the adsorbate species, gain more translational entropy than is lost by the adsorbate molecules, thus allowing the prevalence of randomness in the system ${ }^{5,12,18}$. From the results, we could make out that more efficient physisorption. Enhancement of adsorption capacity of the activated carbon at higher temperatures has attributed to the enlargement of pore size and activation of the adsorbent surface ${ }^{11}$. 
Table 6. Equilibrium constant and thermodynamic parameters for the adsorption of metal ions onto acid activated carbon.

\begin{tabular}{cccccccccccc}
\hline Nickel & \multicolumn{1}{c}{$\mathrm{K}_{\mathrm{o}}$} \\
\cline { 2 - 11 } ion, $\mathrm{mg} / \mathrm{L}$ & $30{ }^{\circ} \mathrm{C}$ & $40{ }^{\circ} \mathrm{C}$ & $50{ }^{\circ} \mathrm{C}$ & $60{ }^{\circ} \mathrm{C}$ & $30{ }^{\circ} \mathrm{C}$ & $40{ }^{\circ} \mathrm{C}$ & $50{ }^{\circ} \mathrm{C}$ & $60{ }^{\circ} \mathrm{C}$ & $\Delta \mathrm{H}^{\circ}$ & $\Delta \mathrm{S}^{\circ}$ \\
\hline 10 & 3.85 & 4.33 & 4.93 & 5.82 & 3.39 & 3.81 & 4.28 & 4.87 & 11.30 & 48.37 \\
20 & 3.17 & 3.43 & 3.73 & 4.06 & 2.90 & 3.21 & 3.52 & 3.88 & 6.95 & 32.47 \\
30 & 2.34 & 2.50 & 2.67 & 2.85 & 2.14 & 2.38 & 2.64 & 2.91 & 5.52 & 25.27 \\
40 & 1.82 & 1.92 & 2.03 & 2.19 & 1.51 & 1.71 & 1.91 & 2.18 & 5.06 & 21.79 \\
50 & 1.53 & 1.61 & 1.68 & 1.77 & 1.06 & 1.23 & 1.39 & 1.58 & 4.08 & 16.98 \\
\hline
\end{tabular}

$\Delta \mathrm{H}^{\circ}(\mathrm{kJ} / \mathrm{mol}), \Delta \mathrm{S}^{\circ}(\mathrm{J} / \mathrm{K} / \mathrm{mol}), \Delta \mathrm{G}^{\circ}(\mathrm{kJ} / \mathrm{mol})$

\section{Kinetics of adsorption}

Kinetics of sorption describes the solute uptake rate, which in turn governs the residence time of sorption reaction. It is one of the important characteristics in defining the efficiency of sorption. In the present study, the kinetics of the nickel ion removal has carried out to understand the behaviour of this low cost carbon adsorbent. The adsorption of nickel ion from an aqueous solution follows reversible first order kinetics, when a single species considered on a heterogeneous surface. The heterogeneous equilibrium between the nickel ion solution and the activated carbon have expressed as

$$
\mathrm{A} \underset{\mathrm{k}_{2}}{\stackrel{\mathrm{k}_{1}}{\rightleftarrows}} \mathrm{B}
$$

Where, $\mathrm{k}_{1}$ is the forward rate constant and $\mathrm{k}_{2}$ is the backward rate constant. A represents nickel ion remaining in the aqueous solution and $\mathrm{B}$ represents nickel ion adsorbed on the surface of activated carbon. The rate constants calculated as earlier ${ }^{11,12,13}$. The data furnished in Table 7 , is evident that the forward rate constant is much higher than the backward rate constant suggesting that the rate of adsorption is clearly dominant. At equilibrium, the rate is the ratio of the concentration of adsorbate in adsorbent and concentration of adsorbate in aqueous solution given by $\mathrm{K}_{0}$. The calculated values presented in the Table 6 . The results indicates that $\mathrm{K}_{0}$ values decreases with increase in the concentration of the nickel ion and increases with increase in temperature

A clear examination of the effect of nickel ion concentrations on the rate constant $\mathrm{K}_{\mathrm{ad}}$ (Table 7), the values help to describe the mechanism of metal ion removal taking place .In cases of strict surface adsorption a variation of rate should be proportional to the first power of concentration. However, when pore diffusion limits the adsorption process, the relationship between initial nickel ion concentration and rate of reaction will not be linear. It shows that pore diffusion limits the overall rate of nickel ion adsorption ${ }^{12}$

The contact-time experimental results can be used to study the rate-limiting step in the adsorption process, as shown by Weber and Morris ${ }^{13,14}$. Since the particles are vigorously agitated during the adsorption period, it is probably reasonable to assume that the rate is not limited by mass transfer from the bulk liquid to the particle external surface, one might then postulate that the rate-limiting step may be either film or intraparticle diffusion. As they act in series, the slower of the two will be the rate-determining step ${ }^{13}$.

The rate constant for intraparticle diffusion is obtained using the equation

$$
\mathrm{Q}=\mathrm{K}_{\mathrm{p}} \mathrm{t}^{1 / 2}+\mathrm{C}
$$

Here, $K_{p}(\mathrm{mg} / \mathrm{g} / \mathrm{min})$ is the intraparticle diffusion rate constant. The $\mathrm{K}_{\mathrm{p}}$ values obtained from the slope of the linear portions of the curves (Figure 5). The $K_{p}$ values increased with increase in the nickel ion concentration, which reveals that the rate of adsorption is governed by the diffusion of adsorbed nickel ion within the pores of the adsorbent. 


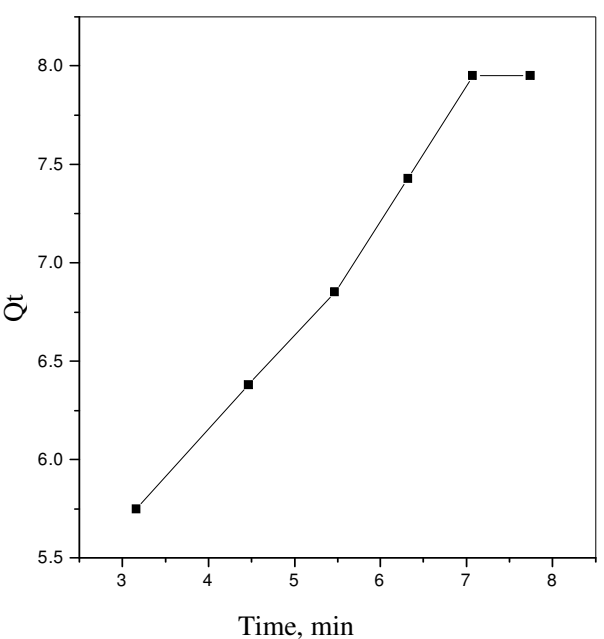

Figure 5. Intraparticle diffusion effect on the adsorption of nickel ion.

$[\mathrm{Ni}]=10 \mathrm{mg} / \mathrm{L}$;Contact time $=60 \mathrm{~min}$; Adsorbent dose $=50 \mathrm{mg} / 50 \mathrm{~mL}$

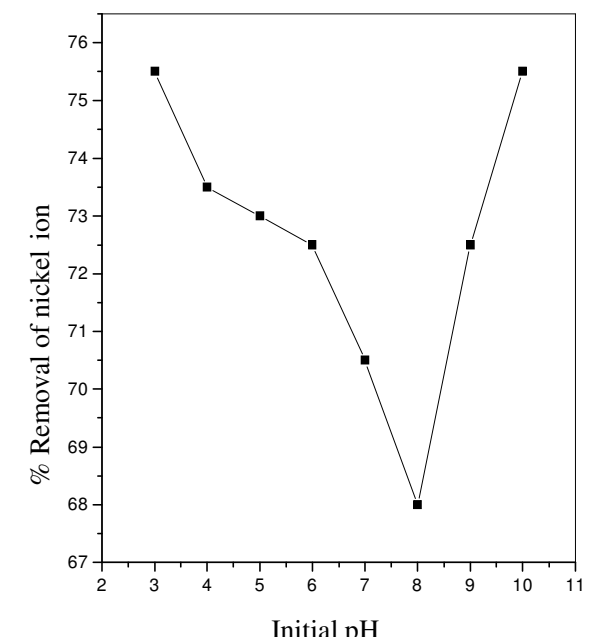

Figure 6. Effect of $\mathrm{pH}$ on the adsorption of nickel ion.

$[\mathrm{Ni}]=30 \mathrm{mg} / \mathrm{L} ;$ Contact time $=60 \mathrm{~min}$; Adsorbent dose $=50 \mathrm{mg} / 50 \mathrm{~mL}$

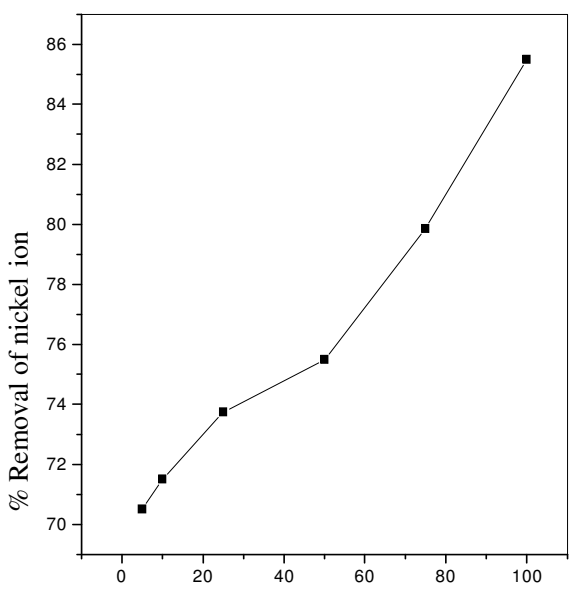

Concentration of chloride ion in $\mathrm{mg} / \mathrm{mL}$

Figure 7. Effect of other ions on the adsorption of nickel ion.

$[\mathrm{Ni}]=30 \mathrm{mg} / \mathrm{L} ; \mathrm{pH}=7 ;$ Contact time $=60 \mathrm{~min}$; Adsorbent dose $=50 \mathrm{mg} / 50 \mathrm{~mL}$

Table 7. Rate constants for the adsorption of nickel ions $\left(10^{3} \mathrm{k}_{\mathrm{ad}}\right.$, $\left.\mathrm{min}^{-1}\right)$ and the constants for forward $\left(10^{3} \mathrm{~K}_{1}\right.$, $\left.\min ^{-1}\right)$ and reverse $\left(10^{3} \mathrm{~K}_{2}, \min ^{-1}\right)$ process

\begin{tabular}{|c|c|c|c|c|c|c|c|c|c|c|c|c|}
\hline \multicolumn{13}{|c|}{ Temperature, ${ }^{\circ} \mathrm{C}$} \\
\hline \multirow{2}{*}{$\begin{array}{c}\text { Nickel ion } \\
(\mathrm{mg} / \mathrm{L})\end{array}$} & \multicolumn{4}{|c|}{$\mathrm{k}_{\mathrm{ad}}$} & $\mathrm{k}_{1}$ & $\mathrm{k}_{2}$ & $\mathrm{k}_{1}$ & $\mathrm{k}_{2}$ & $\mathrm{k}_{1}$ & $\mathrm{k}_{2}$ & $\mathrm{k}_{1}$ & $\mathrm{k}_{2}$ \\
\hline & $30^{\circ}$ & $40^{\circ}$ & $50^{\circ}$ & $60^{\circ}$ & \multicolumn{2}{|c|}{$30^{\circ}$} & \multicolumn{2}{|c|}{$40^{\circ}$} & \multicolumn{2}{|c|}{$50^{\circ}$} & \multicolumn{2}{|c|}{$60^{\circ}$} \\
\hline 10 & 218.11 & 258.46 & 312.63 & 399.08 & 173.16 & 44.95 & 209.99 & 48.47 & 259.94 & 52.69 & 340.54 & 58.54 \\
\hline 20 & 165.35 & 184.97 & 208.58 & 236.77 & 125.66 & 36.69 & 143.22 & 41.75 & 164.51 & 44.07 & 190.07 & 46.70 \\
\hline 30 & 110.01 & 119.89 & 131.34 & 143.45 & 77.07 & 32.94 & 85.62 & 34.27 & 95.60 & 35.74 & 106.24 & 37.21 \\
\hline 40 & 80.37 & 86.08 & 91.98 & 101.63 & 51.90 & 28.47 & 59.68 & 29.40 & 61.66 & 30.32 & 69.97 & 31.76 \\
\hline 50 & 65.26 & 69.25 & 72.95 & 77.84 & 39.74 & 26.02 & 42.69 & 26.56 & 45.74 & 27.21 & 49.77 & 28.07 \\
\hline
\end{tabular}




\section{Effect of $p H$}

The experiments carried out at different $\mathrm{pH}$ shows that there was a change in the percent removal of nickel ion over the entire $\mathrm{pH}$ range of 3 to 10 shown in the Figure 6, $\mathrm{pH}$ is one of the most important parameters controlling the adsorption process. The effect of $\mathrm{pH}$ of the solution on the adsorption of nickel ion on MCC was determined. The result is shown in Figure 6 . The $\mathrm{pH}$ of the solution was controlled by the addition of $\mathrm{HCl}$ or $\mathrm{NaOH}$. The uptake of nickel ions at $\mathrm{pH} 8$ was the minimum and a maximum in uptake was obtained at $\mathrm{pH}$ 3.0. However, when the $\mathrm{pH}$ of the solution was increased (more than $\mathrm{pH} 7$ ), the uptake of nickel ions was increased. It appears that a change in $\mathrm{pH}$ of the solution results in the formation of different ionic species, and different carbon surface charge. At $\mathrm{pH}$ values lower than 5 , the nickel ions can enter into the pore structure ${ }^{17}$ may be due to its small size.

At a $\mathrm{pH}$ value higher than 9 , the existence of $\mathrm{MCC}$ surface $\mathrm{OH}^{-}$creates a competition between nickel ion and it will decrease the aggregation of nickel, which causes an increase in the adsorption of nickel ions on the carbon surface. The effect of the charge on the carbon surface and the electrostatic force of attraction and repulsion between the carbon surface and the nickel ions cannot explain the outcome.

\section{Effect of other ions}

The effect of sodium chloride on the adsorption of nickel ion on MCC is shown in Figure 7. In a low solution concentration $\mathrm{NaCl}$ had little influence on the adsorption capacity. At higher ionic strength the adsorption of nickel ion will be increased due to the partial neutralization of the positive charge on the carbon surface and a consequent compression of the electrical double layer by the $\mathrm{Cl}^{-}$anion. The chloride ion can also enhance adsorption of nickel ion onto MCC by pairing of their charges and hence reducing the repulsion between the nickel ions adsorbed on the surface. This initiates carbon to adsorb more of positive nickel ions ${ }^{17,18}$.

\section{Desorption studies}

Desorption studies help to elucidate the nature of adsorption and recycling of the spent adsorbent and the nickel ion. If the adsorbed nickel ion can be desorbed using neutral $\mathrm{pH}$ water, then the attachment of the nickel ion of the adsorbent is by weak bonds. If sulphuric acid or alkaline water desorp the nickel ion, then the adsorption is by ion exchange. If organic acids, like acetic acid can desorp the nickel ion, then the metal ion has held by the adsorbent through chemisorption. The effect of various reagents used for desorption studies indicate that hydrochloric acid is a better reagent for desorption, because we could get more than $80 \%$ removal of adsorbed nickel ion. The reversibility of adsorbed metal ion in mineral acid or base is in agreement with the $\mathrm{pH}$ dependent results obtained. The desorption of metal ion by mineral acids and alkaline medium indicates that the nickel ion was adsorbed onto the activated carbon through by physisorption mechanisms ${ }^{11-13,18}$.

\section{Conclusions}

The experimental data correlated reasonably well by the Langmuir and Freundlich adsorption isotherms and the isotherm parameters were calculated. The amount of nickel ion adsorbed increased with increase in $\mathrm{pH}$ of the medium. The amount of nickel ion adsorbed slightly decreased with increasing ionic strength and increased with increase in temperature. The dimensionless separation factor $\left(\mathrm{R}_{\mathrm{L}}\right)$ showed that the activated carbon could be used for the removal of nickel ion from aqueous solution. The values of $\Delta \mathrm{H}^{\circ}, \Delta \mathrm{S}^{\circ}$ and $\Delta \mathrm{G}^{\circ}$ results shows that the carbon employed has a considerable potential as an adsorbent for the removal of nickel ion. 


\section{Acknowledgement}

The authors acknowledge sincere thanks to Mrs. Mala Arivoli, The Principal, H. H The Rajah's College Government Arts College, Pudukkottai and The Director of Collegiate Education, Chennai for carrying out this research work successfully.

\section{References}

1. Arivoli S, Kinetic and thermodynamic studies on the adsorption of some metal ions and dyes onto low cost activated carbons, Ph D., Thesis, Gandhigram Rural University, Gandhigram, India, 2007.

2. Sekaran G, Shanmugasundaram K A, Mariappan M and Raghavan K V, Indian J Chem Technol., 1995, 2, 311.

3. Selvarani K, Studies on low cost adsorbents for the removal of organic and inorganics from water, Ph D., Thesis, Regional Engineering College, Thiruchirapalli, India, 2000.

4. Jia Y F and Thomas K K, Langmuir, 2002, 18, 470-478.

5. Namasivayam C, Muniasamy N, Gayathri K, Rani M and Renganathan K, Biores Technol., 1996, 57, 37.

6. Namasivayam C and Yamuna R T, Environ Pollut., 1995, 89, 1.

7. Langmuir I, J Am Chem Soc., 1918, 40, 1361.

8. Freundlich H, Z Phys Chemie, 1906, 57, 384.

9. Krishna D G and Bhattacharyya G, Appl Clay Sci., 2002, 20, 295.

10. Arivoli S, Viji Jain M and Rajachandrasekar T, Mat Sci Res India, 2006, 3, 241-250.

11. Arivoli S and Hema M, Int J Phys Sci., 2007, 2, 10-17.

12. Arivoli S, Venkatraman B R, Rajachandrasekar T and Hema M, Res J Chem Environ., 2007, 17, 70-78.

13. Arivoli S, Kalpana K, Sudha R and Rajachandrasekar T, E J Chem., 2007, 4, 238-254.

14. Weber W J, Principle and Application of Water Chemistry, Edited by Faust S D and Hunter J V Wiley, New York, 1967.

15. Renmin Gong, Yingzhi Sun, Jian Chen, Huijun Liu and Chao yang, Dyes and Pigments, 2005, 67, 179.

16. Vadivelan V and Vasanthkumar K, J Colloid Interf Sci., 2005, 286, 91.

17. Yupeng Guo, Jingzhu Zhao, Hui Zhang, Shaofeng Yang, Zichen Wang and Hongding $\mathrm{Xu}$, Dyes and Pigments, 2005, 66, 123-128.

18. Sreedhar M K and Anirudhan T S, Indian J Environ Protect., 1999, 19, 8. 


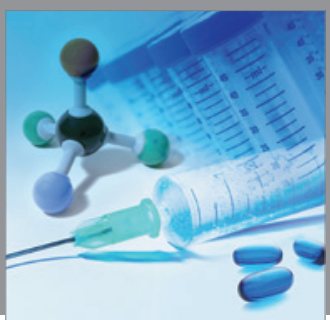

International Journal of

Medicinal Chemistry

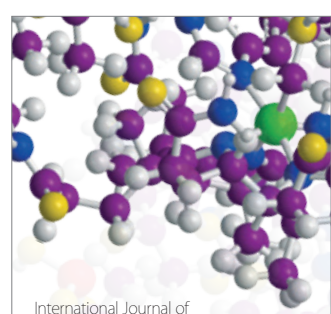

Carbohydrate Chemistry

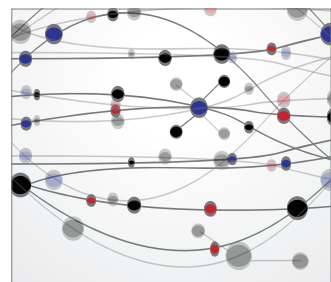

The Scientific World Journal
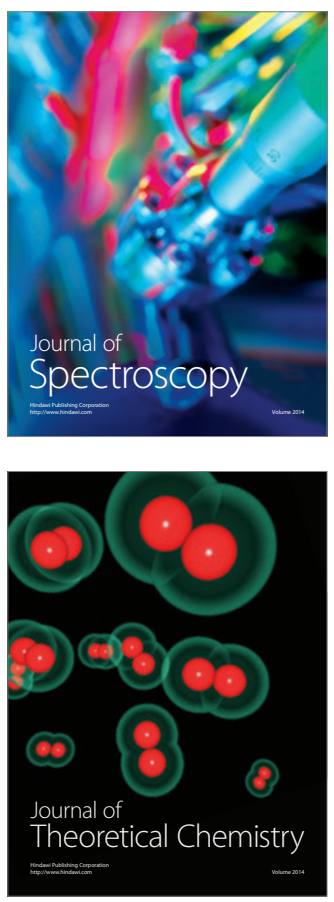
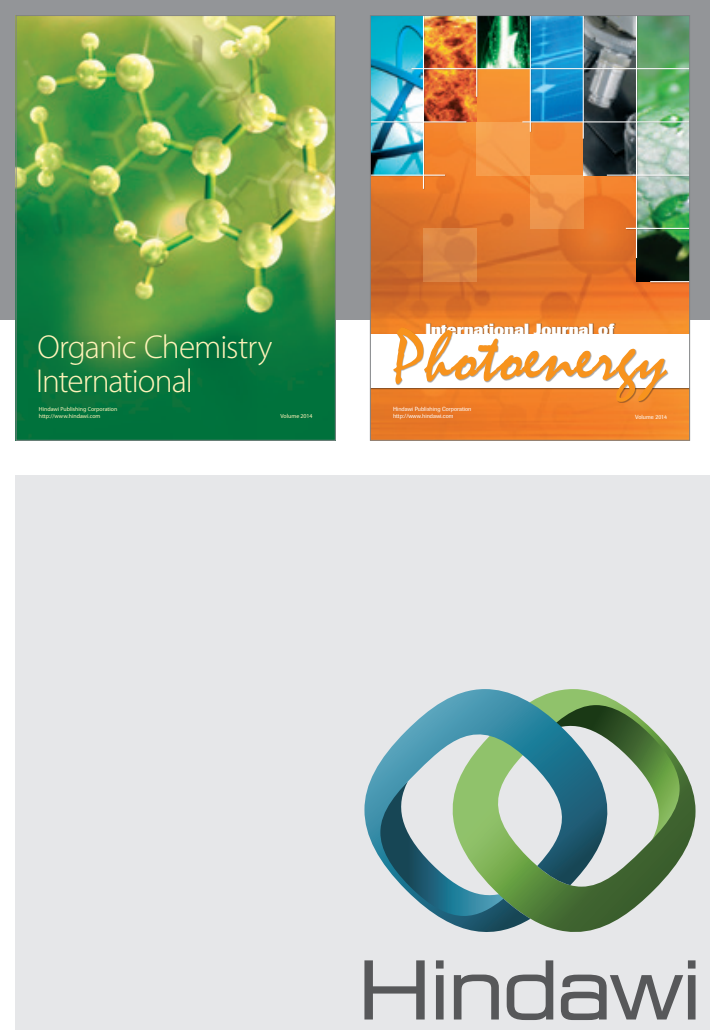

Submit your manuscripts at

http://www.hindawi.com
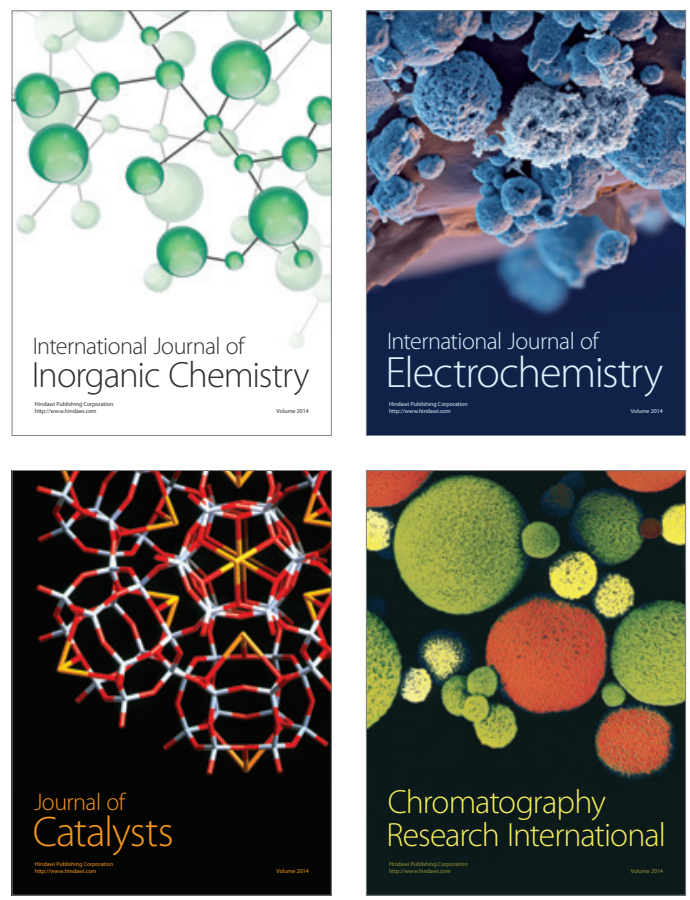
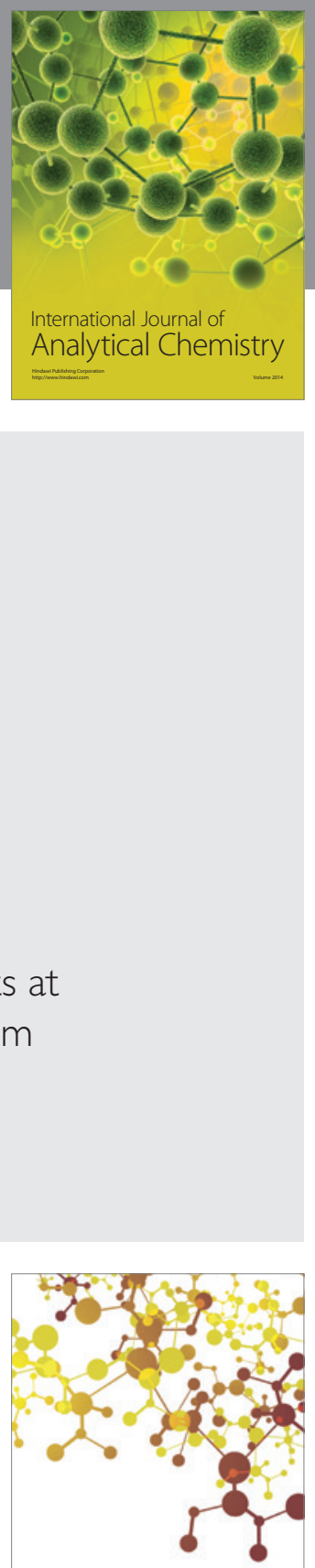

Journal of

Applied Chemistry
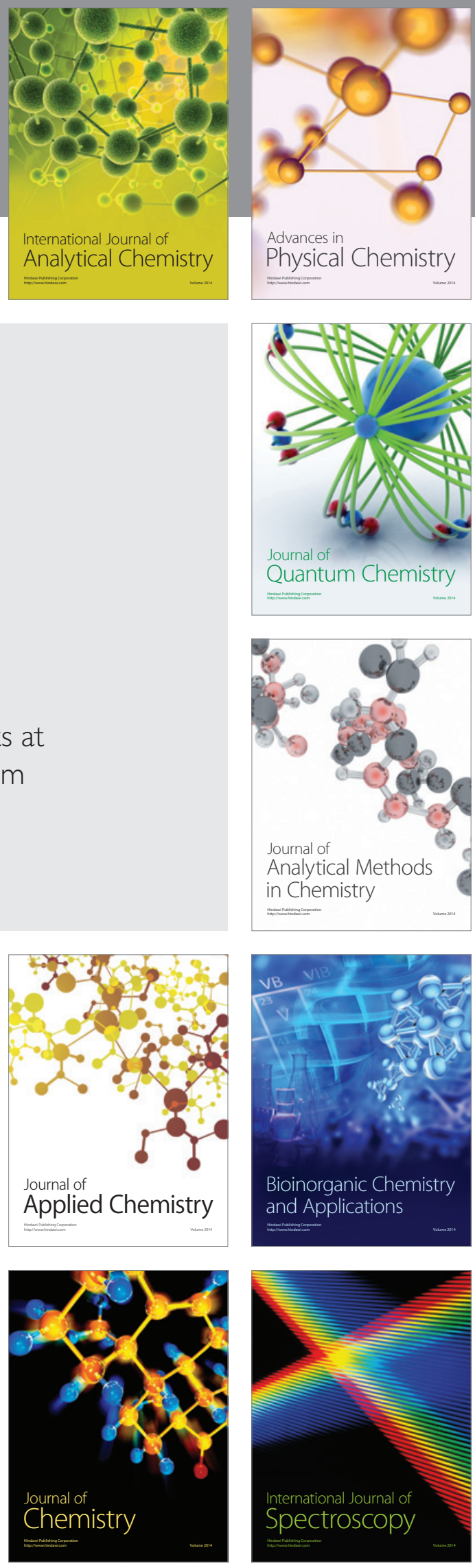